\title{
LA DOCTRINA UTILITARISTA INGLESA EN LA UNIVERSIDAD COLOMBIANA DEL SIGLO XIX
}

\author{
Dra. Miryam Báez Osorio ${ }^{1}$ \\ Universidad Pedagógica y Tecnológica de Colombia \\ Grupo de Investigación HISULA - SHELA \\ mbaezosorio@yahoo.es
}

Recepción: 30/05/2008

Evaluación: 28/01/2009

Aceptación: 20/03/2009

Articulo de Reflexión

\section{RESUMEN}

En la Nueva Granada hoy república de Colombia se habló por primera vez del autor inglés, Jeremías Bentham en 1811 cuando Antonio Nariño publicó en el periódico La Bagatela un artículo en donde se resaltaba su obra. Muchos personajes como Antonio Nariño, Simón Bolívar y Francisco de Paula Santander, utilizando su sistema epistolario, comentarios de otros autores y el análisis de textos, lograron conocer los planteamientos sobre la doctrina utilitarista, realizados por Jeremías Bentham y les pareció interesante y útil para los proyectos de la época, por lo cual lo incluyeron en la enseñanza de Legislación Civil y Penal de las Universidades y Colegios. Así, Bentham facilitó el proyecto educativo de Santander y en buena parte de los gobiernos radicales de Colombia de la segunda mitad del Siglo XIX, especialmente en lo relacionado con la instauración de la escuela laica.

Palabras Claves: Bentham, Radicales, Escuela Laica, Política, Estado, Educación, Utilitarismo, Proyecto Educativo, Universidad, Legislación.

\footnotetext{
1 Doctora en Ciencias de la Educación de RUDECOLOMBIA, Magíster en Historia actualmente es Docente del Doctorado en Ciencias de la Educación e investigadora del grupo Historia y Prospectiva de la Universidad Latinoamericana HISULA, ha publicado más de 20 libros y capítulos de libros.
} 


\title{
THE ENGLISH UTILITARISM DOCTRINE IN THE COLOMBIAN UNIVERSITY OF THE XIX CENTURY
}

\author{
Dra. Miryam Báez Osorio \\ Universidad Pedagógica y Tecnológica de Colombia \\ HISULA - SHELA Research Group \\ mbaezosorio@yahoo.es
}

\begin{abstract}
In the new Grenada, today Republic of Colombia, for the first time, English author Jeremy Bentham was mentioned, when in the newspaper "La Bagatela", Antonio Nariño published an article highlighting his work in 1811. Many people such as Antonio Nariño, Simón Bolívar and Francisco de Paula Santander, using their correspondence system, comments about other authors and Jeremy Bentham's text analysis, knew the utilitarian doctrine approach. They deemed it interesting and useful and applicable to that time projects. This is why they decided to include it in the Civil and Penal Law taught in the universities and high-schools. Thus, Bentham helped Santander's educational project carried out a great deal as well as those of the radical Colombian governments in the second half of the nineteenth century, especially regarding the establishment of the secular school.
\end{abstract}

Key Words: Bentham - Radicals - Secular School - Politics - State - Education Utilitarianism - Education Project - University - Legislation.

\section{INTRODUCCIÓN}

El inglés Jeremías Bentham fue quien formuló más claramente la doctrina del utilitarismo, a pesar de que Hobbes y sobre todo Locke habían colocado ya las bases del principio de utilidad. Bentham sistematizó la ideología de una Inglaterra preocupada principalmente por la eficacia y el bienestar de la especulación política. El utilitarismo, era una filosofía comercial, una mecánica, una contabilidad.

En principio, Bentham se preocupó sobre todo por las reformas sociales y la reforma de las prisiones, del procedimiento legal y de la organización judicial y no consideraba a la política más que como un medio de asegurar el orden y de concluir las 
reformas sociales que le interesaban. Bentham evolucionó hacia el radicalismo democrático, en parte bajo la influencia de James Mill. En adelante se demostró partidario de un poder fuerte y bien armado para la acción (Inglaterra estaba en guerra con Napoleón) y sostuvo la teoría de la democracia representativa pura: sufragio universal, soberanía del pueblo, estricta subordinación de los gobernantes a los gobernados.

Aquí en tierras de América, la doctrina utilitarista de Jeremías Bentham se integró a los planes de estudio de la Gran Colombia del año 1826, estudio que se consideró dentro de la Legislación universal, civil y penal. En éste contexto, se mira la penetración de tales postulados, las obras de Bentham, los sucesos y las actitudes de los criollos con respecto a las ideas de Bentham y el concepto de Bentham relacionado con las ideas sobre la política y el estado.

\section{Penetración de las Ideas de Jeremías Bentham a Colombia}

De Jeremías Bentham se habló por primera vez en Colombia en el año de 1811, cuando Nariño publicó en el periódico La Bagatela un artículo de un Autor Español en donde se hacía resaltar el concepto de Bentham sobre la Libertad de Imprenta, al decir que en ningún tiempo se podían presentar con más utilidad sus pensamientos que en ese momento en que se trataba de revisar la constitución. Así mismo agregaba que si la libertad de imprenta ocasionaba males particulares que la hacía abominable a los ojos del hombre fanático y pacífico, también traía bienes incalculables para el público siendo el mal de las luces y el antemural del despotismo. Esto demuestra el deseo del autor de poner en tela de juicio las ideas de Bentham sobre la libertad de imprenta, la cual estaba concebida en lo siguiente

Siendo el beneficio que resulta de la imprenta libre, mayor que el que resultaría de no tener que temer sus inconvenientes, el gozar de la libertad de la imprenta sería en último resultado un bien, aunque de él hubieran de seguirse todos los males al que puede dar origen. ${ }^{2}$

Bentham manifestaba expresamente el beneficio ocasionado por la libertad de imprenta, la presentaba como la solución a los problemas de opresión y silencio a que estaban sometidos en ese momento los criollos. Posteriormente, el 13 de Agosto de 1825, Jeremías Bentham escribió desde Londres a Simón Bolívar dando a conocer sus trabajos sobre legislación y expresaba de la siguiente manera

$1^{o}$. Principios que deben servir de guía en la formación de un código constitucional para un Estado. $2^{\circ}$. Declaración o protesta de los miembros del cuerpo legislativo al tomar posesión de su destino. $3^{\circ}$. Otro escrito que lleva en Inglés el título de "oficial aptitud de maximised, expense minimised" (La eficacia

2 NARIÑO, Antonio. (1947): "LABAGATELA", en Publicaciones del Ministerio de Educación

de Colombia. Biblioteca Popular de Cultura. Bogotá. Litografía y Editorial Cahur, pp. 114 -146. 
La doctrina utilitarista inglesa en la universidad colombiana del Siglo XIX

de los empleos públicos - llevada a su máximum y los gastos a su mínimum). $4^{\circ}$.Cuadro ordenado de las materias que contienen el código constitucional según demuestran los títulos de sus capítulos y secciones. En el último escrito mencionado se expone un sistema de Remuneración de Empleos, combinado con otro Sistema de Enseñanza para Empleos, que puede al mismo tiempo servir como sistema de enseñanza nacional, sin aumento de gastos para el gobierno. ${ }^{3}$

A la comunicación mencionada anteriormente, el Libertador contestó el 15 de enero de 1827, en donde expresaba a Bentham no haber recibido las obras expuestas en su carta. Igualmente, le mencionó el deseo de aprovechar la oferta hecha por el pensador inglés en la misma misiva al recomendar el envío de jóvenes a prepararse en la escuela de Hazelwood, cerca de Londres. Como le informaba no haber recibido las obras se las mandó pedir en los siguientes términos

Espero con ansia que la bondad de usted se sirva dirigirme nuevamente las obras de Legislación Civil y Judicial juntamente con las de Educación Nacional para estudiar en ellas el Método de hacer bien y atender la verdad, únicas ventajas nos ha concedido en la tierra y que usted, ha devuelto maravillosamente prodigando con profusión sus goces a los individuos de nuestra desgraciada especie, que largo tiempo sufrirá todo el mal y la ignorancia. ${ }^{4}$

Para Simón Bolívar las obras de Bentham contenían el método que enseñaba a hacer bien a los demás y enseñaba la verdad de la vida humana, dándole al individuo pautas para la búsqueda de su felicidad. Así, el Vicepresidente de la Gran Colombia, General Francisco de Paula Santander, por Decreto de 8 de noviembre de 1825, mandó que en todos los colegios en las cátedras se enseñara legislación universal por Jeremías Bentham. Así, el sistema Benthamista se introdujo definitivamente en la educación colombiana mediante el Artículo 168 del 3 de octubre de 1826 que expresaba

Principio de Legislación Universal y de Legislación Civil y Penal. En ésta cátedra que es la mayor importancia para todos los que abrazan la carrera de la Jurisprudencia, serán conocer las leyes naturales que arreglan las obligaciones y derechos de los hombres entre sí, consideraciones individualmente y también formando sociedades políticas. Los tratados de Legislación civil y penal de Bentham servirán por ahora para las lecciones de los diversos ramos que han de enseñarse en ésta cátedra en la que podían estudiarse las Leyes del Rey Gramble. El maestro consultará igualmente los principios de Legislación por un anónimo, la ciencia de la Legislación y las demás obras clásicas que hay sobre varios de los puntos que contiene esa asignatura. ${ }^{5}$

3 MEMORIAS DEL GENERAL O'LEARDY. (1881): Imprenta de la Gaceta Oficial Publicación por su Hijo Simón B. O'Leardy, Tomo XXX. pp. 265-266.

4 MEMORIAS DEL GENERAL O'LEARY. (1887): Cartas del Libertador. Caracas. Imprenta y Litografía del Gobierno Nacional. Tomo XXXI. p. 319.

5 MEMORIAS DEL GENERAL O'LEARY. (1887): Cartas del Libertador. Caracas, Imprenta y Litografía del Gobierno Nacional. Tomo XXXI. p. 319 [Decreto Sobre Principios de Legislación Universal y de Legislación Civil y Penal], en: Miscelánea de Cuadernos. Serie 2a. Tomo 17. Fondo Pineda No. 271. p. 71. 
Aspecto que hace reflexionar en la forma como fueron penetrando las ideas utilitaristas, representadas en la obra de Jeremías Bentham y el interés de los gestores de la nacionalidad colombiana, y entre ellos Antonio Nariño, Simón Bolívar y Francisco de Paula Santander, por la formación jurídica y económica de la juventud. Entre las obras que se conocieron de Jeremías Bentham como uno de los filósofos más sobresalientes estaban: 1) Pragment on Goverment. 2) Introduction to the principles of Morals and Legislation. 3) Principios que deben servir de guía en la formación de un código constitucional para un estado. 4) Declaración o protesta de los miembros del cuerpo legislativo a tomar posesión de su destino. 5) Official aptitude maximizad, expense Minimizad.

Los planteamientos de Bentham en su obra Pragment on Gobernment, eran esencialmente críticos a los comentarios de Blackstone y a través de ella, un ataque a la profesión legal y a la concepción Whing del gobierno inglés; con esto Bentham declaraba su mayor interés en la causa de las reformas legales, y presentaba esquemáticamente la concepción que habría de desarrollar después de una serie larga de libros de jurisprudencia.

En la obra La Introduction to the Principles of Morals and Legislation, Bentham unía la psicología, la ética y la jurisprudencia en torno a las líneas sugeridas ya por Helvencio. El placer y el dolor, aportaban no sólo la norma de valor necesario para una jurisprudencia crítica, sino también las causas de la conducta humana mediante las cuales el legislador hábil podía controlarla y dirigirla.

Sobre la teoría del derecho, Bentham consideraba que el principio de la mayor felicidad, colocaba en manos del legislador capaz un instrumento prácticamente universal. Con él podía fabricar el tejido de la felicidad a través de la razón y el derecho, porque aportaba una teoría de la naturaleza humana básica, con sus valorizaciones y motivaciones, suponiéndolas aplicables a todos los tiempos y lugares.

\section{Esencia del Utilitarismo Inglés}

En el campo del derecho penal, el principio de la utilidad aportaba Bentham un método natural para llegar a una teoría racional de las sanciones. El método técnico parte del supuesto de que el delito merece castigo, pero el concepto de merecimiento es esencialmente indefinible salvo en función de las prácticas o ideas existentes. Fue en su teoría del procedimiento legal y la organización judicial, quizá, donde Bentham desarrolló sus ideas más características y donde aportó más de la tradición liberal.

En su deseo de simplificar el procedimiento y mejorar la eficiencia de los tribunales, proponía abandonar casi del todo los controles y protecciones que habían sido considerados necesarios para proteger los derechos de los súbditos. Bentham extendió aquí al derecho procesal los principios que ya habían adoptado en relación con el derecho constitucional en su obra fragment on goberment. Señaló correctamente que el formalismo legal y las reglas artificiales acerca de la admisión de las pruebas dependían en gran medida de una creencia en que el derecho sustantivo era malo y que el gobierno era peligroso y decía que, "si esta creencia era válida, el remedio racional era mejorar 
la Ley, no debilitar a los tribunales. El formalismo, la oscuridad y los tecnisismos de derecho, sostenía, tienen como resultado un máximo de gastos, demoras y molestias para los litigantes, el privar de la justicia a un gran número de personas y el hacer caprichoso o incierto el resultado de procesos legales ${ }^{6}$.

El ideal de Bentham era que cada hombre fuera su propio abogado. Para este fin propugnaba por la sustitución de los alegatos formales por procedimientos informales ante un árbitro que intentaría la conciliación, la aceptación universal de cualquier tipo de pruebas pertinentes y una gran medida de discreción judicial, en vez de las reglas rígidas, para excluir lo no pertinente. Respecto de la organización de los tribunales, Bentham acababa la práctica, especialmente la de pagar a los jueces y otros funcionarios de los tribunales con honorarios en vez de sueldos.

En suma, Bentham partidario inicialmente de un sistema próximo al despotismo ilustrado, termina en el autoritarismo democrático. Pero la democracia seguía siendo para él un conjunto de individualidades, el producto de un cálculo. La democracia era necesaria para conciliar los intereses individuales de un soberano y los intereses corporativos de la aristocracia.

\section{EI Benthamismo presentado por Historiadores Colombianos del Siglo XIX}

Es interesante conocer la explicación sobre la penetración de las ideas de Bentham, realizada por algunos historiadores del siglo XIX como fue el caso de José Manuel Groot en su obra Historia de la Gran Colombia, Historia Eclesiástica y Civil de la Nueva Granada, en donde el autor tomó cierta actitud contra el vicepresidente de la República y su Ministro de Interior, debido a la promulgación y la Legislación sobre la enseñanza Benthamista (Decreto del 8 de noviembre de 1825) y por este hecho pensaba que ellos podían hacer cuanto quisieran en materia de Religión; y fue así como adoptó una posición defensiva Groot, frente a las ideas y acciones contra la moral en sus referencias a la masonería, a la sociedad bíblica y a la introducción de malos libros. ${ }^{7}$

Para José Manuel Groot, el decreto causó enorme perjuicio porque ahuyentó de las aulas a muchos jóvenes e impedió el ingreso de otros, porque había algunos padres de familia que preferían la moralidad y buenas ideas de sus hijos al brillo de una carrera que no podía menos que hacerse a costa de tan altos intereses; este perjuicio se hizo presente frente al gobierno por medio de la prensa y de diferentes representaciones de las provincias. Este hecho llamó la atención pública por su trascendencia en el orden moral, por la importancia de la materia y por las personas interesadas en la misma. El señor Francisco Margallo y Don Vicente Azuero, fueron los dos personajes principales en esta escena. Al primero lo hacían ver o figuraba como el reo cargado de crímenes y el segundo como autor ofendido injustamente y cuyas virtudes había vulnerado atrozmente el eclesiástico Francisco Margallo.

6 Ibídem., p. 75.

7 GROOT, José Manuel. (1941): Historia de la gran Colombia. Historia Eclesiástica y Civil de la Nueva Granada. Caracas. Academia de Historia de Venezuela Tomo V. Cooperativa de Artes Gráficas, pp. 431-445. 
A mediados de 1827 era general el clamor público contra las enseñanzas de Bentham. De todas las provincias, se enviaron comunicaciones al Vice-presidente pidiendo que se variase el texto de Legislación o se suprimiese esta enseñanza. El General Santander y Vicente Azuero habían estado haciendo frente a la serie de ataques mediante sus artículos en la Gaceta, en que defendían a Bentham, no entrando en el análisis de sus doctrinas para así poder demostrar su bondad, o por lo menos proclamar que no eran tan peligrosas como se decía, sino que se entendían en palabras de injuria contra quienes las combatían por razones poderosas y sostenían que todo eso no era sino egoísmo, fanatismo e ignorancia. Pero habiendo llegado a tales términos la indignación general, el Vice-presidente no pudo menos que dictar providencia sobre el particular.

Como en su mismo plan de estudios planteaba la designación de textos de legislación como provisoria, cualquiera creía que su resolución era variar de texto. Pero no, cuando se usó de la palabra provisionalmente no fue más sino la de disimular por el momento; Bentham era el alma del plan de estudios y quitarlo, era matarlo. Por lo tanto, el ejecutivo resolvió que el catedrático enseñara la Legislación de Bentham, admitiendo que el autor tenía algunas cosas malas, las cuales no debían seguirse. Los miembros de la Dirección General de Estudios que informaron sobre el particular fueron el señor José Manuel Restrepo, Vicente Azuero y el doctor Vergara. El primero se separó de este dictamen e informó que el autor era malo y debía reemplazarse por otro. Pero en la Gaceta se publicó sólo el informe favorable a la enseñanza por Bentham y el de Restrepo, se omitió.

Igualmente, el historiador José Manuel Restrepo en su obra Historia de la Nueva Granada, expuso cómo Santander en su Administración gubernamental se preocupó por el fomento de la instrucción pública y fue así como en cada establecimiento se iban presentando certámenes públicos a los cuales concurrían las autoridades, en muchas ocasiones el mismo Santander para presenciar el adelanto de los educandos. Sin embargo, muchos de estos actos literarios fueron causa de disgusto por parte de los padres de familia por cuanto se notaba allí en la enseñanza a sus hijos de Ideologías anticatólicas consignadas en la obra del Conde de Tracy y los principios de Legislación de Bentham. Sabiendo el pueblo que dichas enseñanzas eran contrarias a los principios de la Religión Católica, profesada por la mayoría de los granadinos, no podían de ninguna manera estar de acuerdo con ellas. ${ }^{8}$

También, Joaquín posada Gutiérrez en su Obra Memorias Histórico Políticas, ${ }^{9}$ informó sobre la autorización del Congreso al Ejecutivo para reformar el plan de las Universidades y los colegios, en cuya virtud prohibió que se continuasen enseñando los principios de Legislación de Bentham. Para Posada Gutiérrez, esta medida fue tomada con base en el clamor y en los deseos de los padres de familia que temblaban

\footnotetext{
8 RESTREPO, José Manuel. (1936): Historia De La Nueva Granada. Bogotá. Editorial Minerva Biblioteca Aldeana de Colombia.

9 POSADA GUTIÉRREZ, Joaquín. (1929). Memorias Histórico Política Tomo I. Bogotá. Segunda Edición. Imprenta Nacional.
} 
por sus hijos ante las enseñanzas del principio de utilidad. Principio que para él era propagado por un publicista pernicioso y había sido mal enseñado y mal comprendido; por lo tanto los estragos habían sido muchos en el país. Dice Posada que tal medida se volvió cuestión de estado y los enemigos del Libertador Simón Bolívar la explotaron para arremeter contra él, valiéndose de la juventud. Pensaba el autor que los padres de familia se fijaban mucho en los textos, y no veían lo más importante: los maestros.

Pues creía que se debía tener sumo cuidado porque eran los maestros los encargados de dar las explicaciones de los diferentes problemas y los ilustró al respecto con un ejemplo sobre el Evangelio al decir

El Evangelio explicado por un Cristiano es el libro de los libros por Excelencia, es la Moral puesta en Acción, es la verdad enseñada por Dios Mismo; explicado por un incrédulo, es un disparatorio absurdo pernicioso; es la mentira autorizada por la ignorancia. ${ }^{10}$

Esto mostraba con mucha razón el papel que podían desempeñar algunos maestros frente a la juventud y a la sociedad en general, como el caso de los catedráticos de legislación universal por Bentham, ya que eran ellos quienes más podían orientarlos por el camino del bien o por el camino del mal, a través de sus enseñanzas. Para Posada Gutiérrez eran más peligrosos los maestros benthamistas que el mismo texto de Bentham, las consecuencias de éste dependían en gran parte de la manera como se explicara o se enseñaran tales ideas.

\section{Actitudes de los Criollos Frente a las Ideas de Bentham}

Los tratados de legislación de Bentham fueron objeto de estudio y meditaciones de los criollos en tiempo de la dominación Española por cuanto en reuniones secretas los forjadores de la Independencia se dedicaron a comentar obras de ilustres pensadores y entre ellas tuvieron las del autor inglés mencionado. También muchos de los dirigentes criollos citaban a Bentham en sus discursos y en sus reuniones con notable admiración y veneración; lo cual hace pensar que fue un momento oportuno en que se presentó Jeremías Bentham con sus doctrinas ante una sociedad cansada y hastiada de la opresión española, y que encontraba allí la posible solución a sus inquietudes y diversos problemas. Dicha legislación ofrecía un código sistemático de virtudes burguesas que se acoplaban bien a los impulsos y deseos del grupo integrado por comerciantes, abogados e individuos de su edad.

A este grupo dirigente le llamó la atención el concepto de bienestar y placer de Bentham; lo cual unido a las necesidades y tendencias de la época, le afianzaron a las clases dirigentes durante un largo tiempo su poderío y confianza; porque venía una tendencia de la vida moderna de llevar al estado a las formas y sistemas propios de la economía capitalista, ya que como dice Jaime Jaramillo Uribe en su obra el El

10 Ibídem., p. 112.

Rhela. Vol. 12. Año 2009, pp. 96 - 110 
Pensamiento Colombiano en el Siglo XIX, después de una guerra en donde se había transformado la maquinaria burocrática de la nación, permitía se ajustara a los intereses de la naciente burocracia de la Nueva Granada.

Los ciudadanos formados en principios de la religión católica, comenzaron a dejar oír su voz de protesta y así como se fue generalizando el estudio de las obras del autor Inglés, también se fue impregnando la repulsión hacia él; en tal forma que algunos opinaban todavía hacia 1836 el por qué el gobierno seguía insistiendo con mantener la enseñanza de la Legislación Benthamista cuando el mismo comprendía y veía la razón del rechazo que ejercía un gran sector de la población de la Nueva Granada. Se consideraba que seguir manteniendo esa enseñanza era buscar que la juventud rompiera con sus creencias religiosas, morales y sembrar la inquietud política que los llevaba al caos y a la desorientación total.

En esas condiciones lo mejor que podía hacer el Legislador era seguir el espíritu o ciertas pautas de la población, porque como decía un autor anónimo: Nosotros nada hacemos mejor que lo que practicamos libremente, conforme a nuestro juicio natural.

El sentimiento popular que forma la conciencia social de una nación debe ser respetado por sus gobernantes. Persistir en una legislación que no llenaba los intereses en la mayoría de la población Neogranadina era buscar la creación de problemas no solo a la masa popular sino a todos los sectores. Desde la imposición de la enseñanza de Legislación Benthamista, diferentes personajes dejaron sentir su protesta, su rechazo y hasta su reconocimiento de los errores que según ellos encontraban en las tesis Benthamistas. Fue así como los intelectuales Felix de Restrepo y Francisco Margallo, rechazaron de plano a Bentham por considerarlo un autor pernicioso. Los dirigentes Vicente Azuero y Estanislao Vergara, miembros de la Dirección General de Estudios, confesaban que los libros de Bentham contenían proposiciones erróneas en materia religiosa. ${ }^{11}$

Esto hizo que los padres de familia en forma continua y sin descanso elevaran una serie de peticiones al gobierno para buscar la supresión en forma definitiva de esos estudios, haciendo ver, su espíritu cristiano, su amor a la patria y la responsabilidad que tenían frente a sus hijos, les exigía estar en pie de alerta para velar y salvaguardar las instituciones. Fue así como ellos manifestaban que la educación de sus hijos se iba entorpeciendo y perturbando, precisamente desde que comenzaron a enseñar las tesis de Bentham.

También, por eso otros dirigentes insistían se enseñara aquello que no turbara las ciencias religiosas y se instruyera a sus hijos en principios republicanos, porque de lo contrario, era buscar que los padres de familia no matriculasen a sus hijos en los establecimientos educativos o se les estaba obligando a aceptar por la fuerza y a costa

\footnotetext{
11 Observaciones sobre el Decreto del Gobierno publicado en la Gaceta No. 212 de BENTHAM, Jeremías. (1836): La enseñanza de los principios de Legislación. Bogotá. Imprenta José Ayarsa. Fondo Pineda No. 271, p. 5.
} 
de sacrificios lo que el gobierno y unos pocos deseaban se enseñara a los educandos. Lo anterior se afirma en un comentario que publicó la Gaceta en donde con razón se decía que si el congreso y el gobierno conocían con claridad la repugnancia que sentían los padres de familia por la instrucción que se daba a sus hijos con base en Bentham, por qué no se suprimía y allí se aseguraba:

No será colocar a los padres de familia en la dura alternativa, o de privar a sus hijos de una de las pocas carreras, que ofrece el Estado, o sufrir que se imbuyan en doctrinas que ofenden y creen que comprometen su conciencia. ${ }^{12}$

En esa medida, los catedráticos de Legislación Benthamista tuvieron gran responsabilidad. Por esto se decía que el éxito de la enseñanza dependía de las precauciones mantenidas por el catedrático de Legislación Bentamista porque de ese modo aminoraría el peligro que pudiera ocasionar a la juventud dicho aprendizaje. El ejecutivo reconocía, que los principios planteados por Bentham eran opuestos a las doctrinas religiosas y políticas que ofrecía la Nueva Granada; pero manifestaba, no encontrar obra que estuviera adaptada a estos principios religiosos y políticos.

El ejecutivo insistió que el problema radicaba en la falta de una explicación minuciosa y detenida de las tesis de Bentham, pues al poner en manos de una juventud inexperta aquella obra sin hacerle todas las explicaciones del caso, implicaba de hecho caer en errores o difamar contra los principios religiosos, morales y políticos profesados por la nación, lo cual perjudicaría para siempre a la sociedad Neogranadina. Por eso comenta un autor anónimo

La resolución emitida por el gobierno, en tal sentido es para preveer porque la propagación de las tesis de Bentham, sería de todas maneras perjudicial y para que sus teorías no se sobrepongan a las Leyes que prescriben la enseñanza de la Moral. $^{13}$

Hubo reconocimientos por parte del gobierno de los errores y males que podía ocasionar entre la juventud la enseñanza Benthamista, pero continuó obligando a mantener la cátedra, rechazando desde el momento de su implantación en colegios y universidades, a costa de contradecir a la opinión pública. Esto significó, hasta cierto punto, propiciar un descontento general y un desorden en la nación, que en un primer momento pretendía afianzar su verdadera organización republicana y dejar de lado los resquemores surgidos por la guerra de independencia.

Al generarse en la Nueva Granada una serie de hechos de tipo social y político; Bolívar asumió la dictadura, con lo cual hizo acrecentar el malestar social que culminó con el bochornoso atentado al Libertador, lo que se conoce como conspiración septembrina. Fue así como en Octubre de 1828, apareció una circular emitida por el Ministro del Interior, firmada por José Manuel Restrepo quien aseguró respecto a dicha

12 Ibídem, p. 6.

13 Ibídem, p. 6-7. 
conspiración cómo en ese atentado tuvieron mucho que ver los estudiantes universitarios, al exponer

S. E. meditando Filosóficamente el Plan de Estudios ha creído hallar el origen del mal en las ciencias políticas que se han enseñado a los estudiantes al principiar su carrera de Facultad Mayor, cuando todavía, no tienen el juicio bastante para hacer a los principios las modificaciones que exigen las circunstancias peculiares a cada Nación. ${ }^{14}$

Afirmación que podía tener sentido hasta cierto punto por cuanto la juventud en ese momento anhelaba cosas nuevas para sus aprendizajes que fueran en contra de las instituciones coloniales, era rechazar un marco de cosas pre-establecidas que parecían caducas. Despertaba en ellos un interés grande las ideas contrarias a la religión y a las instituciones para tomarlas y ponerlas en vigencia.

Para contrarrestar la acción de Bentham mediante sus obras, el libertador suspendió la cátedra de Legislación Universal, Restrepo cita en la circular ya mencionada las variaciones que hizo el gobierno en el Plan de Estudios, así:

3o.: Quedan suspensas y sin ejercicio alguno por ahora las cátedras de Principios de Legislación Universal, de Derecho Público, Político, Constitución y Ciencia Administrativa, y por consiguiente que ningunos sueldos se paguen a sus catedráticos. ${ }^{15}$

El Ejecutivo no suprimió definitivamente la Cátedra en mención porque reconocía su importancia, solo lo hacía temporalmente tal vez mientras se conocía otro autor que llenara los intereses de la Nación y satisficiera a la corriente tradicionalista.

\section{El Concepto de Política y Estado en Jeremías Bentham}

Es interesante estudiar la forma como Bentham planteaba sus tesis respecto a la política y el Estado. Los postulados de Bentham chocaron contra los intereses de la nación y la sociedad, muchos consideraban que en donde se propagaba esa doctrina se convertía en víctima de muchas desgracias porque estaban convencidos que Bentham atacaba los intereses de la patria; sus escritos, en cierta manera eran subversivos; el sistema Bentham era perturbador del orden público; sus tesis turban las relaciones morales y mutuas garantías.

En el documento El Benthamismo descubierto a la luz de la razón con respecto a las obras de Bentham y Bonin, se decía lo siguiente:

Nosotros pensamos primero que no deben haber clases de legislación Universal ni de ciencia administrativa; 2o. Que las obras de Bentham y Bonin

14 EDUCACION PÚBLICA. Circular. Publicación en Gaceta No.382 de Octubre 30 de 1828.

15 Ibídem., p. 2. 
no merecen la calificación de obras clásicas, no son completas, ni sus principios son conformes a la moral natural, ni a la religión católica, ni a los principios políticos de la Nueva Granada. Por consiguiente pensamos que las obras mencionadas no servirían para la enseñanza de nuestra juventud y deberían abrogarse su estudio. ${ }^{16}$

Por su parte, el escritor G.T. en su texto Observaciones sobre el Decreto del Gobierno acerca de la enseñanza de legislación por Jeremías Bentham exponía que la doctrina de Bentham era contraria a la profesada por la nación neogranadina ${ }^{17}$. De igual manera, en el panfleto titulado El Cuchillo de San Bartolomé un autor anónimo daba a conocer el hecho de que Bentham ataca los intereses de la patria y se dice allí entre otras cosas

Si la causa, sobre los detestables de Jeremías Bentham solo mirara mis particulares intereses, lo dejaría gustoso en el sepulcro que le fabricaron sus mismos partidarios; pero la gloria de la religión que él observase; los intereses de la patria que agravia; y la educación de la juventud que pervierte me obligan a tomar nuevamente la pluma en obsequio del público poco inteligente, pues los hombres sensatos están en mi favor y no necesitan de mis reflexiones. ${ }^{18}$

También, la idea de los escritos de Bentham son subersivos era sostenida, en principio por un autor anónimo cuyo escrito se denomina Prohibición de la Enseñanza por Bentham. También, el escritor G.T. En su documento Observaciones sobre el Decreto del Gobierno, expresaba la manera como los principios de Legislación benthamista contenían doctrinas erróneas, contrarias a la religión, a la moral y a la tranquilidad pública, que no podían adoptarse. Además se decía que de los principios de legislación benthamista resultaban consecuencias impías, inmorales, impolíticas y absurdas. ${ }^{19}$

De otro lado, la opinión sobre el sistema de Bentham es perturbador del orden Público era expuesta por varios críticos, entre ellos, por Teófilo en su escrito Carta sobre la enseñanza por Bentham en la clase de legislación en donde planteaba: Una ciencia como la de Bentham no puede presentar un cuerpo de doctrina seguro, sino cuando su cultivo en diversos pueblos, bajo diversas zonas, influencias morales y políticas, reúna la meditación y la experiencia de los siglos. ${ }^{20}$

Igualmente un autor anónimo en la nota titulada Prohibición de la Enseñanza por Bentham emitida del Senado de la República afirma la doctrina Benthamista trastorna

\footnotetext{
16 "El Benthamismo Descubierto a la luz de la razón" o Documentos Importantes para los padres de familia, extractados del Constitucional de Popayán (1836). Imprenta José Ayarsa. Bogotá Biblioteca Nacional. Fondo Pineda No. 271.

17 G.T. "Observaciones sobre el Decreto del Gobierno Publicado en la Gaceta No. 212". p. 6.

18 EL CUCHILLO DE SAN BARTOLOMÉ. (1827): Bogotá, Imprenta de Espinosa, Biblioteca Nacional, Fondo Pineda. No. 639.

19 G.T. "OBSERVACIONES sobre el Decreto del Gobierno publicado en la Gaceta No. 212. p. 30.

20 TEOFILO "Carta sobre la enseñanza por Bentham en la clase de Legislación”. p. 338.
} 
la tranquilidad pública y el buen orden social. ${ }^{21}$ También sobre el mismo aspecto el escritor G.T. En su texto Observaciones sobre el Decreto del Gobierno, prevenía cómo después de la misma tempestad política que vivía el país, se trastornaría el orden social debido a las enseñanzas Benthamistas. Por ejemplo anotaba

Y aún después que la tempestad política se serene tiemble el padre que su hijo Benthamista, no abrevie, como Tiberio, los dias de su existencia, para anticiparse la posición de su fortuna. Tiemble el marido ver quebrantada la fe conyugal que le ha jurado su esposa, si otra mano con Epicúrea la prometa más placeres que la suya. Tiemble ella por su parte de igual inconstancia y perfidia de su marido materialista, marchita la flor de su primera edad. ${ }^{22}$

Así otras tantas ideas relacionadas con el rechazo y defensa de las enseñanzas con ideas de Bentham se plantearon a través de muchos escritos en periódicos, panfletos, discursos, sermones y cartas.

En síntesis, algunos pensadores de la Nueva Granada dieron a conocer las tesis Benthamistas respecto de la política y el Estado. Dentro de dichas tesis se ve que: chocaban contra los intereses de la nación, pues su doctrina no estaba de acuerdo con la moral natural, ni con los principios de la religión católica, ni a los principios políticos de la Nueva Granada; donde fueran propagadas, la sociedad se consideraba que era acreedora de muchas desgracias; atacaban los intereses de la patria; por considerarse subversivas, pues su doctrina se basa en el principio de utilidad y entiende como tal buscar el placer, huir del dolor, de lo cual resultaban consecuencias impías, inmorales, apolíticas y absurdas; perturban el orden público, ya que su sistema atentaba contra la existencia del orden social que reposa sobre la Ley natural, luego trastorna la tranquilidad y el buen orden social, turban las relaciones morales y mutuas garantías que en esto reposa la recíproca confianza; fundamentaban que la mayor constitución para un pueblo era aquella a que estaba acostumbrado, presentando una gran indiferencia por las instituciones políticas; está contra la ley, Bentham conoce que una ley inflexible es ineficaz puesto que no tiene en cuenta sexo, edad, fortuna, clase, educación y preocupaciones morales y religiosas.

\section{CONCLUSIONES}

Colombia comenzó a interesarse por Inglaterra debido a varios motivos: en primer lugar desde el proceso de la Independencia aquel país Europeo procuró brindar su apoyo para que la Nueva Granada consiguiera su emancipación de España, a costa de quedar dependiendo económicamente de Inglaterra, pues con el otorgamiento de empréstitos en condiciones anormales para la economía, una vez conseguida la independencia política, la Nueva Granada quedó bajo la orientación de la política

\footnotetext{
21 Prohibición de la Enseñanza por Bentham. p. 343.

22 G.T. Observaciones sobre el Decreto del Gobierno Publicado en la Gaceta. p. 30.
} 
económica de la Gran Bretaña. En segundo lugar, se habían introducido desde la misma época de la dominación española, una serie de libros de filósofos de la ilustración que imprimieron cierto sentido de libertad, es decir, se presentaba un cambio en la mentalidad de los criollos, lo cual dio lugar a gran atracción por todo lo que viniera de Europa y especialmente de Inglaterra.

Fue así como al presentarse entre los criollos las obras de Bentham con su filosofia utilitarista surgió notable interés por conocerla y copiarla, pues existía un inmenso deseo por imitar todo lo Inglés. También porque se sabía y preveía que en el utilitarismo se buscaba armonía para todos. Además, porque Inglaterra era propulsora del ideal de la búsqueda de un hombre económico el Homo Economicus con lo cual había despertado gran admiración y atracción hacia aquel país que se perfilaba como uno de los más industriales de la época.

Es de anotar cómo en la Gran Colombia se presentaron actitudes diferentes con respecto a la doctrina de Bentham. Algunos estamentos sociales se dedicaron a hacer estudios concienzudos sobre las tesis benthamistas concluyendo que tales doctrinas eran perjudiciales e inútiles para la juventud. Uno de los grupos de presión que más protestó por la enseñanza de legislación benthamista, además de los padres de familia, fue el Clero que analizó y vio con gran desconfianza la introducción de tales enseñanzas, por cuanto después de su examen detenido comprendió que tales doctrinas: atacaban la moral cristiana; eran sensualistas, con lo cual formaba hombres sin conciencia, propugnaba por un individualismo que giraba en la esfera de los placeres; además tenían inmerso un ateísmo y un materialismo desmedido que relajaba las prácticas de la fe cristiana e insinuaba ideas totalmente contrarias a la religión católica y a la Moral.

\section{FUENTES}

DECRETO SOBRE PRINCIPIOS DE LEGISLACIÓN UNIVERSAL Y DE LEGISLACIÓN CIVIL Y PENAL en Miscelánea de Cuadernos. Serie 2a. Tomo 17. Fondo Pineda No. 271.

DECRETO DEL GOBIERNO publicado en la GACETA No. 212 acerca de la enseñanza de los principios de Legislación por Jeremías Bentham. Bogotá, Imprenta por J. Ayarza, año de 1836. Fondo Pineda No. 271.

CONGRESO DE CÚCUTA. (1821): Constitución y Leyes. Biblioteca del Banco Popular. Volumen 21. Bogotá, Editorial Nelly.

EDUCACION PÚBLICA. Circular. Publicación en Gaceta No.382 de Octubre 30 de 1828.

EL CONSTITUCIONAL DE BOYACÁ. (Tunja). Domingo 24 de febrero de 1838. Biblioteca Nacional, Fondo Quijano Otero, No. 352.

INFORME DEL VICERRECTOR DE LA UNIVERSIDAD CENTRAL EN EL AÑO DE 1840. Archivo Nacional. Instrucción Pública. Tomo 115.

EL BENTHAMISMO DESCUBIERTO A LA LUZ DE LA RAZÓN o Documentos Importantes para los padres de familia, extractados del Constitucional de Popayán. Bogotá, Imprenta José Ayarza. 1836. Biblioteca Nacional. Fondo Pineda No. 271. 
PROHIBICIÓN DE ENSEÑANZA POR BENTHAM. (1836): Bogotá, Imprenta de Antonio Mora Pelaez, Biblioteca Nacional. Fondo Pineda No. 470.

\section{SELECCIÓN BIBLIOGRÁFICA}

BENTHAM, Jeremías. (1881): Carta al Libertador Bolivar. Londres, 13 de agosto 1825, en Memorias del General O'leardy. Imprenta de la Gaceta Oficial Publicación por su Hijo Simón B. O'Leardy, Tomo XXX.

BOLÍVAR, Simón. (1827): Carta Señor Jeremías Bentham. Caracas, enero 15 de 1827, en memoras del General O'leardy. Imprenta de la Gaceta Oficial Publicación por su Hijo Simón B. O’Leardy, Tomo SAXO.

CORTAZAR, Roberto. Cartas y Mensajes de Santander. Bogotá, Editorial de la Librería de Voluntad, 1853-1956.10 volúmenes.

Correspondencia dirigida al General Santander. Bogotá, Editorial de la Librería de Voluntad, 1964-1967. 9 volúmenes.

EL CUCHILLO DE SAN BARTOLOMÉ. (1827): Bogotá, Imprenta de Espinosa, Biblioteca Nacional, Fondo Pineda. No. 639.

GROOT, José Manuel. (1941): "HISTORIA DE LA GRAN COLOMBIA. HISTORIA ECLESIÁSTICA Y CIVIL DE LA NUEVA GRANADA”. Academia de Historia de Venezuela. Cooperativa de Artes Gráficas. Caracas. Tomo V.

MEMORIAS DEL GENERAL O'LEARDY. (1881): Imprenta de la Gaceta Oficial Publicación por su Hijo Simón B. O’Leardy, Tomo XXX.

NARIÑO, Antonio. (1947): "LA BAGATELA". Publicaciones del Ministerio de Educación de Colombia, Bogotá, Biblioteca Popular de Cultura. Litografía y Editorial Cahur.

POSADA GUTIÉRREZ, Joaquín. (1929): Memorias Histórico Política. Bogotá. Segunda Edición. Imprenta Nacional.

RESTREPO, José Manuel. "HISTORIA DE LA NUEVA GRANADA". Biblioteca Aldeana de Colombia. Editorial Minerva, Bogotá 1936.

TEOFILO. (1835): Carta sobre la enseñanza por Bentham en la clase de Legislación. Bogotá, Imprenta José Ayarza. Biblioteca Nacional. Fondo Pineda No. 470.

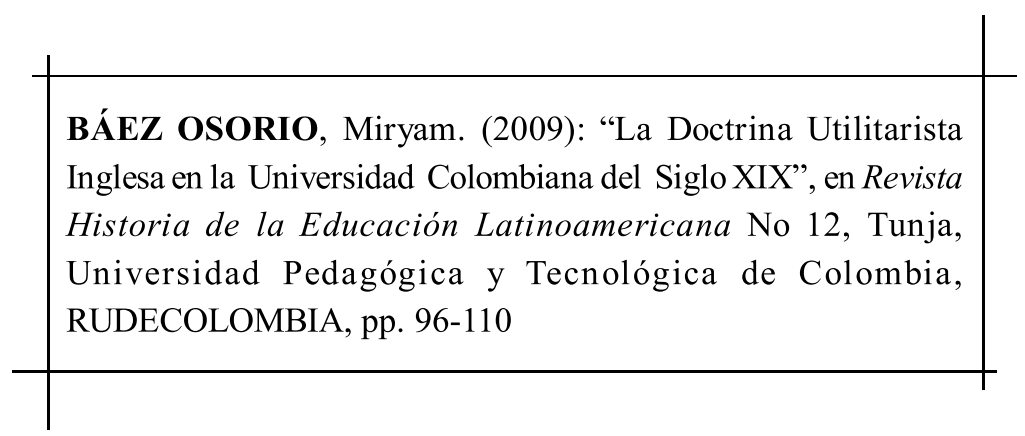

Rhela. Vol. 12. Año 2009, pp. 96 - 110 